\title{
THE UNION DEFENCE FORCES' BUILDINGS OF CAPE TOWN DURING THE SECOND WORLD WAR 1939-45
}

\author{
by Cdr W.M. Bissett*
}

Recently the Cape Provincial Institute of Architects has compiled and published catalogues of the buildings of Cape Town. There can be no doubt that the Second World War was the "finest hour" in the Mother City's history. The Cape Fortress Location List contains details of all the buildings and sites occupied by the Union Defence Forces and certain British units in the Cape Command during this hectic period. During the War the information was classified as secret.

Only six copies of the Location List were made and they had been completed by 4 August 1944. The Location list was prepared by the ' $Q$ '
Section at the Castle and updated from time to time.

Since the information concerning the units occupying the buildings in Cape Town may be of considerable interest to the Cape Provincial Institute of Architects, the National Monuments Council and others and has not been published before, it is provided below. There has also been great interest in the Table Bay Docks and its buildings so details concerning these have also been included.

${ }^{*}$ Cdr W.M. Bisset is staff officer SA Naval Museums

\begin{tabular}{|c|c|c|}
\hline Building & Street & Unit(s) based there: 4 August 1944 \\
\hline The Castle & Castle Street & $\begin{array}{l}\text { Cape Fortress Headquarters } \\
\text { Union Defence Experimental Station Intercom } \\
\text { Women's Auxiliary Army Services Headquarters } \\
\text { Combined Operations } \\
1 \text { Heavy Battery } \\
\text { SA Corps of Signals } \\
\text { DCRE } \\
\text { Air Force Liaison Officer } \\
\text { Cape Peninsula Rifles guards } \\
\text { Military Police Corps } \\
\text { Trigonometrical Survey } \\
\text { Pigeon Services Headquarters } \\
\text { Recruiting Huts } \\
\text { Red Cross Society } \\
\text { Dental Clinic } \\
\text { Medical Huts } \\
\text { South African Women's Auxiliary Services } \\
\text { Staff Officer Cadets } \\
\text { RAF Police }\end{array}$ \\
\hline New Drill Hall & Tennant Street & $\begin{array}{l}6 \text { 'Q' Stores } \\
\text { Assistant Director of Medical Services, FP\&Q } \\
\text { Assistant Director of Medical Services (Hygiene } \\
\text { Section) } \\
\text { Physical Training Officer }\end{array}$ \\
\hline
\end{tabular}




\section{Map №. l. CENT R A CA PE TOW N}

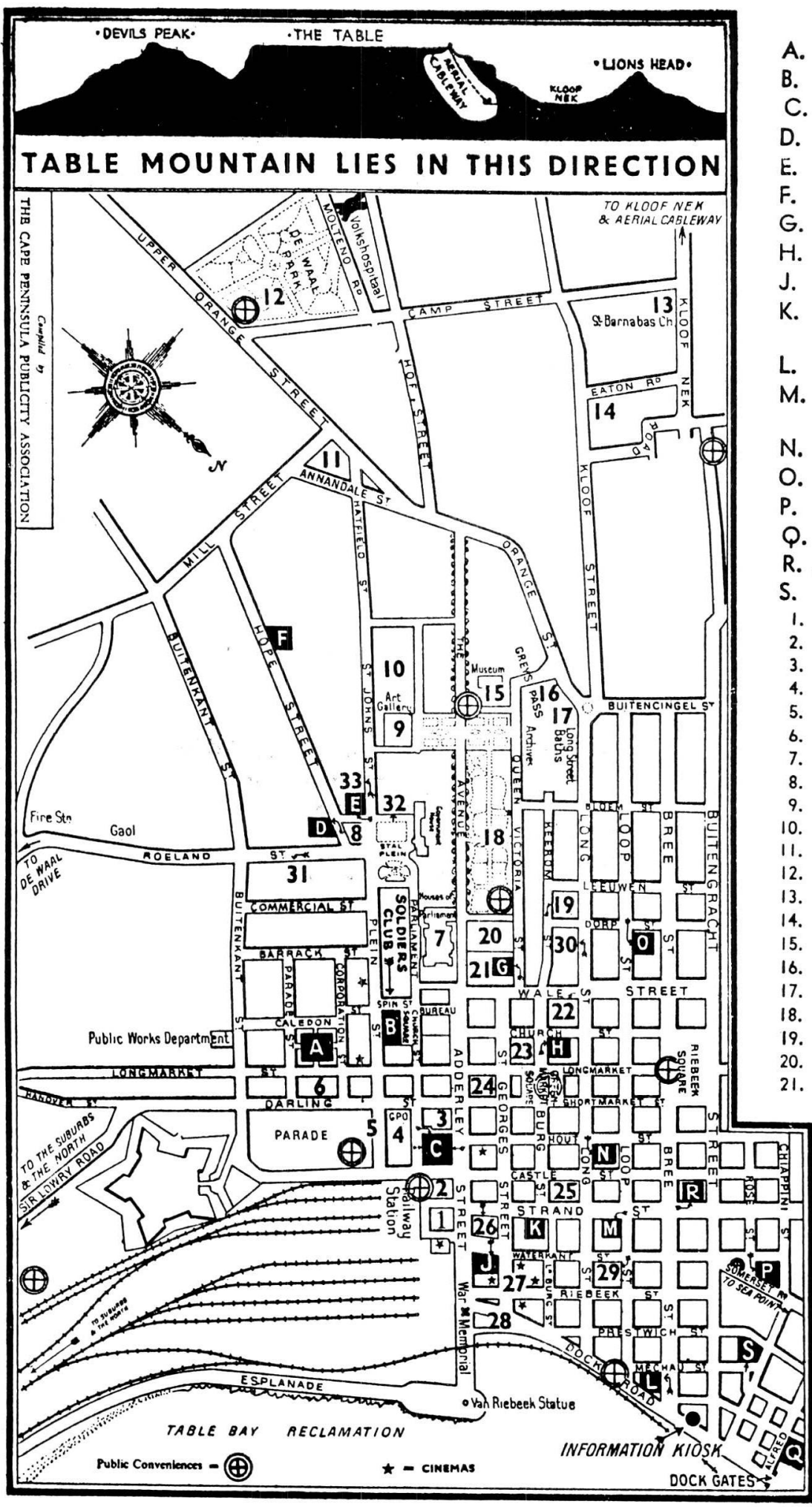

DON'T TALK ABOUT SHIPS OR SHIPPING!
I N D E X

A. MAYOR'S GARDEN CANTEEN

B. SOLDIERS' CLUE

C. OLD POST OFFICE BUILDING

D. CATHOLIC SERVICE CLUB

E. UNION JACK CLUB

F. ZIONIST HALL CANTEEN

G. CATHEDRAL HALL

H. METHODIST CHURCH HALL

J. GOOD CHEER CLUB

K. MERCHANT NAVY WELCOME CLUB

L. CHINESE SAILORS' CLUB

M. LOYALIST WAR WORKERS' CANTEEN

N. Y.M.C.A.

O. SALVATION ARMY REST-ROOMS

P. ST. ANDREW'S CHURCH HALL

Q. SEAMEN'S INSTITUTE

R. AMERICAN CLUB

S. INDIAN SEAMEN'S CLUB.

I. VISITORS' INFORMATION BUREAU

2. RAILWAY STATION

3. STANDARD BANK

4. GENERAL POST OFFICE

5. BUS TERMINUS \& FRUIT MARKET

b. CITY HALL

7. HOUSES OF PARLIAMENT

8. ST. MARY'S CATHEDRAL (R.C.)

9. NATIONAL ART GALLERY

0. SYNAGOGUE,

1. PRESBYTERIAN CHURCH

2. DE WAAL PARK

3. ST. BARNABAS CHURCH

4. CONGREGATIONAL CHURCH

5. MUSEUM

6. CHRISTIAN SCIENCE CHURCH

7. LONG STREET BATHS

8. MUNICIPAL GARDENS

19. NEDERLANDSCHE CLUB

20. PUBLIC LIBRARY

21. ST. GEORGE'S CATHEDRAL

22. BAPTIST CHURCH

23. MICHAELIS ART GALLERY

24. BARCLAYS BANK

25. KOOPMANS-DE WET MUSEUM 26. THOS. COOK \& SON

7. CINEMAS:-PLAZA, COLOSSEUM ALHAMBRA, ROYAL 18. COLOURED SOLDIERS' INSTITUTE 29. DEN NORSKE FORENING

30. GREEK SAILORS' CLUB

31. BRITISH TEMPLE

32. DE GOEDE HOOP TEMPLE

33. DE GOEDE TROUW TEMPLE

YOU ENTER THE CITY FROM THE DOCKS AT THIS POINT 


\begin{tabular}{|c|c|c|}
\hline & & 12 Medical Depot \\
\hline & & 24 Coast Defence Corps \\
\hline & & 21 Fortress Signals \\
\hline & & 25 Fortress Signals \\
\hline & & Repository Store \\
\hline & & Chaplains \\
\hline & & Information Officer \\
\hline Grand Parade & Castle Street & 11 Motor Transport Depot \\
\hline CL 10 Colosseum & St George's Street & 17 Lines of Communication \\
\hline Boston House & Strand Street & Movement Control \\
\hline & & Imperial Movement Control \\
\hline & & Deputy Assistant Provost Marshal \\
\hline & & Air Force Embarkation \\
\hline Robb Motors & Strand Street & $\begin{array}{l}61 \text { Coast Defence Corps and Special Signals } \\
\text { Services }\end{array}$ \\
\hline Williams Hunt & 172 Longmarket Street & Sub Supply Depot \\
\hline & 19 Loop Street & Director of War Supplies \\
\hline National Mutual & Church Square & Assistant Director of Medical Services \\
\hline Buildings & & SA Women's Auxiliary Services \\
\hline Geneva House & Church Square & Director of Coast Artillery \\
\hline Old Mutual Buildings & Darling Street & $\begin{array}{l}\text { Director and Assistant Director of Fortification and } \\
\text { Coastal Works }\end{array}$ \\
\hline & & SA Naval Forces \\
\hline Old Supreme Court & Adderley Street & Chief Stores Inspector \\
\hline & & Branch Pay Office \\
\hline & & $\begin{array}{l}\text { Women's Auxiliary Army Services Medical and } \\
\text { Recruiting }\end{array}$ \\
\hline & & Women's Auxiliary Defence Corps \\
\hline & & Chaplains \\
\hline & & Court Martials \\
\hline & & SA Women's Auxiliary Services Headquarters \\
\hline & & War Graves Commission \\
\hline & & Estates and Negotiations \\
\hline & & SA Naval Forces (Records) \\
\hline & & Director of Military Intelligence \\
\hline & & Information and Education Bureau \\
\hline Marks Buildings & Parliament Street & Secretary for Defence \\
\hline & & Estates Negotiations \\
\hline & & Sessional GHQ \\
\hline & & Chief of the General Staff \\
\hline Old General Post Offic & Adderley Street & Officers' Club \\
\hline & & Signals Club \\
\hline
\end{tabular}




\begin{tabular}{|c|c|c|}
\hline Building & Street & Unit(s) based there: 4 August 1944 \\
\hline & & $\begin{array}{l}\text { Ellison House } \\
\text { Welfare Organisation } \\
\text { Indian and Malay Corps } \\
\text { Defence Liaison Officer } \\
\text { Occupational Therapy Centre } \\
\text { Naval Provost Marshal } \\
\text { Free French Club }\end{array}$ \\
\hline Trafalgar Place & Adderley Street & Central Recruiting Depot \\
\hline $\begin{array}{l}\text { New General Post } \\
\text { Office }\end{array}$ & Parliament Street & $\begin{array}{l}\text { Directorate of Military Intelligence, IC Section } \\
\text { Chief Censor }\end{array}$ \\
\hline Good Hope Hall & Plein Street & Government Printer \\
\hline Labour Bureau & Corporation Street & Essential Services Protection Corps \\
\hline Union House & Queen Victoria Street & Director of War Supplies \\
\hline Old Training College & Queen Victoria Street & $\begin{array}{l}\text { Naval Signals } \\
\text { Assistant Director of SF } \\
105 \text { Maintenance Company }\end{array}$ \\
\hline Davis Building & Barrack Street & 6 'Q' Stores \\
\hline Railway Station & Adderley Street & $\begin{array}{l}\text { Garrison Provost Company, Military Police Corps, } \\
\text { Movement Control }\end{array}$ \\
\hline Cape Times Building & St George's Street & Director of Civil Supplies \\
\hline Stuttafords Buildings & St George's Street & Tel Manager \\
\hline University Buildings & Gardens & Orange Street Headquarters, SA Naval Forces \\
\hline Paddock & The Avenue & Coast Artillery Barracks \\
\hline Italian Legation & Orange Street & Coast Artillery officers' mess \\
\hline Dryfe House & Orange Street & Women's Auxiliary Defence Corps Barracks \\
\hline Hotel Edward & Mill Street & Royal Naval Barracks \\
\hline Helmsley Hotel & Hof Street & Women's Royal Naval Service Barracks \\
\hline Lansdowne Villa & Annandale Street & Women's Auxiliary Military Police Corps \\
\hline German Club & Hope Street & $\begin{array}{l}61 \text { Coast Defence Corps and Special Signals } \\
\text { Services }\end{array}$ \\
\hline CL 13 North Gate & Dock Area & SA Naval Forces \\
\hline \multicolumn{3}{|l|}{ Norman Kennedy Site } \\
\hline \multicolumn{3}{|l|}{ Union Castle Company } \\
\hline \multicolumn{3}{|l|}{ North Dockyard } \\
\hline \multicolumn{3}{|l|}{ Fishmarket } \\
\hline \multicolumn{3}{|l|}{ Fire Cubicles } \\
\hline \multicolumn{3}{|l|}{ New Basin } \\
\hline Docks Stores & & \\
\hline
\end{tabular}




\section{Building}

Imperial Cold

Storage Buildings

Farbers Buildings

Power Station

$\mathrm{CH} 6$ Foreshore

HMSAS UNITIE

CL 8 Gantry

Dock Area

HMSAS

BONAVENTURE

CPR Operations Unit

Non-European Docks

Barracks

CL 11 South Arm

Dock Area

Docks Battery

Dock Area

Inner Basin

Reclaimed Ground

CL 1 Yacht Club

North Quay Buildings

North Quay

Chiappini Street

CL 9 New Mole, CL 88 Dock Area and CL 89 New Mole
Unit(s) based there: 4 August 1944

2 Motor Boat Flight

Royal Navy later SA Naval Forces

Cape Peninsula Rifles

1 Heavy Battery Non-European Army Services later SA Naval Forces

11 Motor Transport Company later 1 Heavy Battery Non-European Army Services

1 Heavy Battery

2 Motor Boat Flight

$Q$ and T Stores, SA Naval Forces Magazine

SA Naval Forces later 11 Motor Transport Depot

SA Naval Forces (HMSAS BONAVENTURE II)

T Services Store later Movement Control

Non-European Army Services Barracks

17 Lines of Communication later SA Naval Forces 


\section{BOEKBESPREKINGS/BOOK REVIEWS}

Kol (dr) Jan Ploeger*

\author{
Kmdt C.J. Nöthling (red), Ultima Ratio \\ Regum (The last argument of kings) \\ (Artilleriegeskiedenis van Suid-Afrika) \\ (Artillery History of South Africa) Militêre \\ Informasieburo, SAW/Military Information \\ Bureau, SADF, Publikasie no 8/Publication \\ no 8, Pretoria, 1987, pp 432 met \\ afbeeldings.
}

Op velerlei wyses is verlede jaar aandag aan die 75ste bestaansjaar van die Suid-Afrikaanse Weermag gewy. Binne die bestek van hierdie bespreking mag daar sekerlik in die verband na die inhoud van Militaria $(1987,17 / 2)$ verwys word. Onder die omvattende titel History of the South African Defence Force 1912-1987/ Kroniek van die Suid-Afrikaanse Weermag 1912-1987, is die belangstellende leser ' $n$ oorsig in voëlvlug van die vroeëre Unieverdedigingsmag en die huidige Suid-Afrikaanse Weermag voorgelê.

Elkeen wat hierdie geskiedenis met sy hoogteen laagtepunte, sy tydperke van vrede en oorlog, van uitbreiding en inkrimping ken, sal onder die indruk kom van 'n indrukwekkende vooruitgang en ' $n$ toenemende militêre slaankrag wat, soos die voormalige Hoof van die Suid-Afrikaanse Weermag, genl C. Viljoen, dit so duidelik gestel het, in diens staan van ons eie voortbestaan en die vrye wêreld. Dit is een van die uitstaande kenmerke van die SAW en sy voorganger die UVM.

En met sy blik op die toekoms gerig het die huidige Hoof van die Suid-Afrikaanse Weermag, genl J.J. Geldenhuys, die noodsaak beklemtoon om die krygsgeskiedenis te ontleed met die oog op die uitken van tekortkominge sowel as suksesse. Dan kan, wat die toekoms betref, die mees gewenste resultate tov die toekomstige bloei van die Suid-Afrikaanse Weermag en die suksesvolle aanwending van ons militêre organisasie en sy slaankrag, verwag word. Dit is slegs 'n gedeelte van die aanloop tot die inhoud van 'n omvattende publikasie, waarin die ontwikkelingsgang van die artillerie, na sy vestiging aan die suidpunt van ons land, in woord en beeld weergegee is. In die woorde van die It-genl F.E.C. van den Berg is die inhoud van die huidige eendragtige spanpoging ' $n$ roemryke geskrif wat meer as drie eeue omspan. En terself- dertyd het dieselfde generaal die geslagte van vandag en môre ' $n$ belangrike taak gegee, tw om te verseker dat die artillerie-verhaal van die toekoms ook 'n roemryke geskrif sal vorm.

Oorgaande na die inhoud van hierdie eerste omvattende artilleriegeskiedenis van ons land van 1652 tot onlangs, moet die volgende belangrike punte beklemtoon word: (a) Die feit dat 'n groot aantal medewerkers daarin geslaag het om van die 21 hoofstukke 'n hegte eenheid te vorm. Die onderdele van hierdie eenheid is logies afgebaken en niks is in die verband oor die hoof gesien nie. (b) Die onderskeie skrywersmedewerkers het, behalwe van sekondêre bronne ook - waar dit moontlik was - met vrug en welslae in die slegs hier en daar ontgonne skatte van die SAW-argief gedelf. (c) Hulle het daarin geslaag om ' $n$ verstaanbare oorsig van 'n uiters belangrike onderwerp aan leke en vakkundiges voor te lê. (d) Daar is met vakkennis en insig gesorg om die teks op ' $n$ aanvullende wyse doeltreffend deur middel van passende illustrasies toe te lig.

Die omvangryke inhoud van die werk laat 'n sketsmatige volledige behandeling nie toe nie. Die leser word dus gevra om met die volgende op- en aanmerkings tevrede te wees. In die tyd van die $V O C$ is kanonne op bastions en op ander strategiese posisies naby die Kaapse kasteel opgestel. Forte, batterye, linies en skanse het verrys om 'n landing van vyandelike magte te betwis en om diefstalle vanuit die binneland te belet. Artillerie het deel van die kolonie se seinstelsel gevorm, die artillerie is georganiseer en die beroepsopleiding is in die 18 de eeu ter hand geneem, terwyl die binnelandse verdediging aan die kommando-organisasie toevertrou is.

Tydens die Britse opmars 1795 is tevergeefs pogings deur artilleriste aangewend om teenstand te bied. Die nuwe heersers het die bestaande kusverdediging opgeknap en 'n eie koIoniale artillerie-organisasie in die lewe geroep. In verband met die binnelandse beveiliging het die artillerie, weens gebrek aan teikens, ' $n$ ondergeskikte rol gespeel. Ten spyte van die omstandigheid het, vanaf 1857, op Britse lees geskoeide vrywilliger-artillerie eenhede ontstaan. 